\title{
EMOTIONAL INTELLIGENCE AND FREQUENCY OF ALCOHOL USE DURING ADOLESCENCE
}

\section{INTELIGENCIA EMOCIONAL Y FRECUENCIA DE CONSUMO DE ALCOHOL DURANTE LA ADOLESCENCIA}

\author{
Alejandra Daniela Calero, Juan Pablo Barreyro, Jesica Formoso e Irene Injoque-Ricle \\ Consejo Nacional de Investigaciones Científicas y Técnicas (CONICET) \\ Instituto de Investigaciones, Facultad de Psicología, Universidad de Buenos Aires, Argentina
}

\section{Abstract}

Introduction. Emotional intelligence has proven to be a relevant construct during adolescence and includes three components: attention to feelings, clarity of feelings, and mood repair. Within this age group, alcohol consumption is a central problem. Objective. The aim of this work is to study the relation between emotional intelligence and frequency of alcohol consumption in adolescents that attendant a high school from the Autonomous City of Buenos Aires, Argentina. Methodology. The TMMS-21 was administered to assess emotional intelligence, and an ad hoc questionnaire was administered to assess alcohol consumption. We performed comparisons between age groups and between genders, and we studied the predictive power of emotional intelligence through a lineal regression. Results. Attention to feelings was lower in those adolescents with frequent alcohol consumption. Moreover, results showed that attention to feelings was a predictor of alcohol consumption frequency in women, while age was a predictor of frequency of alcohol consumption for both genders. Conclusion. These findings suggest that alcohol consumption could function as a way of coping with the emotions that are not being attended to.

Keywords: adolescence, alcohol consumption, attention to feelings, Emotional Intelligence, TMMS-21.

\section{Resumen}

Introducción. La inteligencia emocional ha demostrado ser un constructo relevante durante la adolescencia e incluye tres componentes: la atención a los sentimientos, la claridad de los sentimientos y la reparación del estado de ánimo. Dentro de este grupo de edad, el consumo de alcohol es un problema central. Objetivo. Estudiar la relación entre la inteligencia emocional y la frecuencia del consumo de alcohol en adolescentes escolarizados de la Ciudad Autónoma de Buenos Aires, Argentina. Metodología. El TMMS-21 se administró para evaluar la inteligencia emocional, y se administró un cuestionario ad hoc para evaluar el consumo de alcohol. Se realizaron comparaciones entre grupos de edad y entre sexos, y se analizó el poder predictivo de la inteligencia emocional a través de modelo de regresión lineal. Resultados. La atención a los sentimientos era menor en aquellos adolescentes con consumo frecuente de alcohol. Por otra parte, los resultados mostraron que la atención a los sentimientos fue un predictor de la frecuencia de consumo de alcohol en las mujeres, mientras que la edad fue un predictor de la frecuencia de consumo de alcohol para ambos sexos. Conclusiones. Estos hallazgos sugieren que el consumo de alcohol podría funcionar como una forma de lidiar con las emociones que no son correctamente atendidas.

Palabras clave: adolescencia, consumo de alcohol, atención a los sentimientos, Inteligencia Emocional, TMMS-21. 

Salovey and Mayer (1990) coined the term emotional intelligence to refer to a person's ability to perceive, understand and control their emotions and those of others. This ability also allows the person to guide their thoughts and emotions so that it is beneficial for them and for their environment. In like manner, perceived emotional intelligence is the perception that a person has of its own emotional abilities. The model of Salovey et al. (1995) defines three aspects of emotional intelligence: attention to feelings, clarity of feelings, and mood repair. Attention to feelings refers to people's perception of their tendency to focus on observing and rethinking their own emotional experience. Clarity of feelings refers to people's beliefs about their ability to identify their repertoire of emotions, to name them and also, to be able to group them under certain categories. Finally, mood repair refers to people's belief in their ability to regulate negative emotional states, to interrupt negative moods and to prolong positive ones.

Lopes, Salovey, and Straus (2003) found that subjects reporting higher levels of emotional intelligence showed more satisfaction with their social relations. Emotional intelligence is also positively related to indicators of well-being such as quality of life (Bermúdez, Álvarez, \& Sánchez, 2003; Extremera Pacheco, Salguero, \& Fernández-Berrocal, 2011) and negatively with depression (Salovey, Stroud, Woolery, \& Epel, 2002). Nevertheless, Jiménez and López-Zafra (2008) found a positive relation between attention to feelings and depression. Other authors also associated high levels of attention to feelings accompanied by low clarity of feelings and poor mood repair with poor psychological adjustment (Fernández-Berrocal \& Extremera Pacheco, 2008). This would indicate that people who are more emotionally unstable would have greater difficulties in understanding and regulating emotional states, but would be more aware of these emotions, prolonging negative moods (Lischetzke \& Eid, 2003). In the same line, Gohm (2003) argue that ideally, attention to feelings should be present in moderate values since low attention would also be detrimental, as it would not allow a person to use emotional information to make decisions. On the other hand, low clarity when perceiving emotions could keep a person from using cognitive resources to decipher their feelings making it difficult for them to choose a coping strategy (Gohm, Baumann, \& Sniezek, 2001).
Adolescence, along with childhood, is a fundamental life stage for assimilating emotional habits that will govern the rest of our lives (Goleman, 2012). The Emotional skills that the adolescent possesses and develops will influence the functional self-regulation necessary to properly manage and use emotional information. A number of studies using the perceived emotional intelligence model showed that there is a relationship between perceived emotional intelligence and psychological adjustment (Jiménez \& López-Zafra, 2011; Salguero, Palomera, \& Fernández-Berrocal, 2012; Williams, Fernández-Berrocal, Extremera Pacheco, Ramos Díaz, \& Joiner Jr, 2004).

Regarding differences in emotional intelligence between genders, the results observed in previous studies are not conclusive (Sánchez Núñez, Fernández Berrocal, Montañés Rodríguez, \& Latorre Postigo, 2008). Nonetheless, research based on Salovey et al.'s (1995) model reported higher levels of attention to feelings in women (Fernández Berrocal \& Ramos Díaz, 1999; Lasa, Salguero, Fernández Berrocal, \& Aritzeta, 2010; Sánchez Núñez, et al., 2008).

As stated by the Pan-American Health Organization (PAHO, 2015), alcohol consumption is a critical issue in adolescence and is considered a risk-taking conduct. $A$ risk-taking conduct is a behavior that carries potential harm to the person or to others (Furby \& Beyth- Marom, 1992), and during adolescence, those are particularly acute in comparison to adulthood (Chambers, Taylor, \& Potenza, 2003). In fact, one of the riskiest forms of alcohol consumption observed in a young population is the excessive episodic consumption, defined as the intake of a large amount of alcohol (more than 5 units of drink or 60 grams of absolute alcohol in Blood) within a short period of time.

Despite being associated with several dangers at the individual, social and economic levels (Míguez, 2008; Volkow \& Li, 2005), youth culture naturalized alcohol consumption (Míguez, 2009). While at this age all forms of alcohol consumption are considered a risk, certain types are more hazardous, especially if it is early on. Regarding this, the World Health Organization reports that early alcohol consumption in adolescents has increased (WHO, 2008). Epidemiological studies conducted by the Argentine Drug Observatory indicate that alcohol is the psychoactive substance most consumed by this age 
group (OAD, 2012; PAHO, 2014). In the survey conducted in 2014, the World Health Organization observed that $70.5 \%$ of adolescents reported having consumed alcohol being the average initiation age of 13.4 years. Additionally, alcohol was the psychoactive substance most consumed by high school students during their senior year, with a proportion of $62.2 \%$ and an annual incidence of $37.9 \%$. Moreover, during the last month, $50.1 \%$ of the adolescents reported to have taken alcohol and the prevalence of consumption increased together with the age of the respondents, with no significant differences between women and men (PAHO, 2014).

Some of the personal and social factors related to an adolescents predisposition to consume alcohol are: having alcohol-consuming peers (Van Schoor, Bot, \& Engels, 2008), the emotional state (Moral Jiménez, Rodríguez Díaz, \& Sirvent Ruiz, 2005), beliefs or expectations about consumption (Londoño Pérez, García Hernández, Valencia Lara, \& Vinaccia Alpi, 2005), and social stereotypes (Calero, Schmidt, \& Bugallo, 2016). In relation to the regulation of emotions and alcohol consumption, some authors argue that low levels of emotional intelligence lead to poor management of emotions and to high levels of impulsivity, and thereupon to alcohol consumption during adolescence (García del Castillo-López, García del Castillo, \& Marzo Campos, 2012). Another study found an association between poor perception of emotions and a difficulty in using them during substance use, especially in males (Brackett, Mayer, \& Warner, 2004). In a study that analyzed the difference between subjects with alcoholism disorder and controls, it was found that patients suffering from alcohol dependence presented deficits in identification and description of their own emotional states, as well as lower emotion regulation skills; not finding a difference in social skills, recognition of other people's emotions and recognition of mental states (Kopera et al., 2018). Furthermore, different studies reported a negative association between emotional intelligence and alcohol consumption (Austin, Saklofske, \& Egan, 2005; Brackett, et al., 2004; Trinidad \& Johnson, 2002) and also, that low emotional intelligence predicted problematic alcohol consumption (Riley \& Schutte, 2003).

Given the importance of emotion management for individual development, and the problematic that represents in alcohol consumption during adolescence and considering that emotional management has been associated in prior work to alcohol consumption, the aim of this work is to study the relationship between perceived emotional intelligence and frequency of alcohol consumption on this age group.

\section{METHOD}

\section{Participants}

The sample consisted of 399 adolescents (263 females -65.9\%- and 136 males -34.1\%-), with a mean age of 15.14 years $(S D=1.86)$ that attended two private high schools from Buenos Aires, Argentina. Of the total sample, 137 were juniors (mean age $=13.12$, SD $=.39$ ), 139 attended third high school year (mean age $=15.17$, $\mathrm{SD}=.40$ ) and 123 were seniors (mean age $=17.43, \mathrm{SD}=$ .51). The students attended private, middle class schools from Buenos Aires City and surrounding areas.

All the subjects participated with the written consent of their parents, to whom we guaranteed the confidentiality of the information and the anonymity of the participants.

\section{Procedure}

After the schools agreed to participate in the study, students were given a form with information about the investigation so that their parents could authorize them to participate. All students participated with informed consent from their parents. Only those who were not authorized by them were excluded from the study (2\%). The adolescents were informed about the purpose of the investigation and they were guaranteed that the data provided would be anonymous and confidential. A set of self-reported questionnaires were delivered personally to the participants in a sealed envelope to be answered anonymously during school hours and within the classroom avoiding the presence of teachers that may affect the response of adolescents. Only 3 cases where eliminated from the data base because of missing observations.

\section{Instruments}

Trait-Meta Mood Scale (Calero, 2013; based in Salovey et al., 1995). It is a self-reported scale that assesses perceived emotional intelligence through 21 items. It measures self-perception in relation to the ability to 
manage emotions and the stable qualities of emotions. It also allows detecting individual differences in how people respond to emotions (e.g., "I am very attentive to my feelings" ["Estoy muy atento/a a mis sentimientos"]), the clarity with which they do so (e.g., "I usually know my feelings about a situation" ["Usualmente sé cuáles son mis sentimientos acerca de una cuestión o situación"]), and their ability to repair emotional states (e.g., "No matter how bad I feel, I try to think of nice things" ["No importa lo mal que me sienta, trato de pensar en cosas agradables"]) . The person is asked to evaluate the degree to which he/she agrees with each item on a 5-point Likert scale $(1=$ strongly disagree, $5=$ strongly agree). A Cronbach's Alpha coefficient was estimated for each of the subscales, obtaining a value of .79 in attention to feelings, .86 in clarity to feelings and .86 in mood repair. Also, adequate indexes of validity were found in the validation study (Calero, 2013).

Questionnaire on alcohol consumption and frequency. This questionnaire evaluates the frequency of alcohol consumption (e.g., during the last 12 months how often did you drink an alcoholic beverage?), and episodic overdose (e.g., How often do you take 5 or more drinks on the same occasion?). Lower values reflect lower alcohol consumption. It contains ad hoc questions and questions used in Cremonte, Cherpital, Bosges, Peltzer, \& Santángelo (2011) study.

\section{Data analysis}

For each variable, the distribution of the scores was analyzed. Since it was not possible to verify a normal distribution, non-parametric statistical tests were used (see Table 1).

For the group comparisons, Kruskal-Wallis or $\mathrm{U}$ Mann-Whitney tests were used, depending whether single or simultaneous comparisons were performed. In the cases in which a significant difference was observed, the Cliff's Delta was used to quantify the magnitude of the difference. This statistic gives an index between 1 and -1 , the closer it gets to these extremes, the more important the effect size (Cliff, 1993).

To assess the predictive power of emotional intelligence factors (attention to feelings, clarity of feelings, and mood repair) along with age on the frequency of alcohol consumption, a multiple linear regression was performed with the least squares estimation method, having previously checked the assumptions of normality, linearity, homoscedasticity and independence of residues.

\section{RESULTS}

Table 1 includes the descriptive statistics for all variables.

Table 1. Descriptive statistics and Kolmogorv-Smirnov normality test on the TMMS-21 factors

\begin{tabular}{|c|c|c|c|c|c|c|c|}
\hline & Mean & D.S & Skewness & Kurtosis & K-S & df & $p$ \\
\hline Mood repair & 3.57 & .80 & -.46 & -.10 & .09 & 399 & .00 \\
\hline Attention to feelings & 3.64 & .67 & -.35 & .13 & .07 & 399 & .00 \\
\hline Clarity of feelings & 3.39 & .74 & -.46 & -.06 & .10 & 399 & .00 \\
\hline
\end{tabular}

Note: D.S: Standar Deviation. K-S: Kolmogorov Smirnov. Df: degrees of freedom.

Table 2 shows the alcohol consumption frequencies of the general sample, by sex and by school year. Participants were divided into three groups, according to the frequency of alcohol consumption: low from no alcohol consumption to consuming from 6 to 11 times a year, medium when consuming between 1 time per month and 1 to 2 times per week, and high when consuming between 3 or 4 times per week and every day.
This organization was carried out according to the variables distribution.

In order to study whether there were differences in the levels of the emotional intelligence aspects (attention to feelings, clarity of feelings and mood repair) between the frequency of alcohol consumption, comparisons in frequency alcohol consumption were performed. 
Table 2. Frequency of alcohol consumption

\begin{tabular}{|c|c|c|c|c|c|c|}
\hline & Total Sample & Junior & Third-year & Senior & Females & Males \\
\hline Low frequency & $57.1 \%(228)$ & $88.1 \%(118)$ & $61.9 \%(86)$ & $19.8 \%(24)$ & $57.3 \%(149)$ & $59 \%(79)$ \\
\hline $\begin{array}{l}\text { Medium } \\
\text { frequency }\end{array}$ & $39.1 \%(156)$ & $11.9 \%(16)$ & $36.7 \%(51)$ & $73.6 \%(89)$ & $41.9 \%$ (109) & $35.1 \%(47)$ \\
\hline High frequency & $2.5 \%(10)$ & & $1.4 \%(2)$ & $6.6 \%(8)$ & $.8 \%(2)$ & $6 \%(8)$ \\
\hline
\end{tabular}

Note: $\mathrm{n}$ in brackets

A significant difference was observed only in attention to feelings $\left(\chi^{2}(2)=9.66 ; p=.01\right.$ ) (see Table 3 ). The post hoc analysis showed that the differences were significant between low and high frequency $(U=489.00, \mathrm{Z}$ $=-3.11, \mathrm{p}<.01)$, and between medium and high frequency alcohol users $(U=353.00, Z=-2.90, p<.01)$, but not between low and medium frequency alcohol users (see
Table 3). The level of attention to feelings was higher in both cases for adolescents who had a less frequent alcohol consumption. The Cliff's delta showed a medium-high effect size for the between low and highfrequency consumers (-.54), as well as for the difference between low and medium-frequency consumers (-.59).

Table 3. Perceived emotional intelligence aspects and frequency low, medium and high of alcohol consumption

\begin{tabular}{|c|c|c|c|c|c|c|}
\hline & \multicolumn{3}{|c|}{ Mean Rank } & \multirow[b]{2}{*}{$\chi^{2}$} & \multirow[b]{2}{*}{$d f$} & \multirow[b]{2}{*}{$\mathrm{p}$} \\
\hline & Low & Medium & High & & & \\
\hline & $(n=228)$ & $(n=156)$ & $(n=10)$ & & & \\
\hline Attention to feelings & 201.00 & 199.45 & 87.35 & 9.66 & 2 & .01 \\
\hline Clarity of feelings & 200.51 & 192.68 & 204.20 & .48 & 2 & .79 \\
\hline Mood repair & 144.10 & 2.58 & 144.10 & 2.58 & 2 & .28 \\
\hline Third school year & $(n=2)$ & & & & & \\
\hline Attention to feelings & 71.73 & 68.30 & 39.00 & 1.44 & 2 & .49 \\
\hline Clarity of feelings & 71.74 & 66.33 & 88.50 & 1.01 & 2 & .60 \\
\hline Mood repair & 71.29 & 68.75 & 46.50 & .82 & 2 & .66 \\
\hline Juniors & $(n=24)$ & $(n=89)$ & $(n=8)$ & & & \\
\hline Attention to feelings & 66.06 & 63.25 & 20.81 & 11.42 & 2 & .00 \\
\hline Clarity of feelings & 62.46 & 60.95 & 57.19 & .14 & 2 & .93 \\
\hline Mood repair & 58.96 & 62.40 & 51.56 & .81 & 2 & .67 \\
\hline Female & $(n=149)$ & $(n=109)$ & $(n=2)$ & & & \\
\hline Attention to feelings & 133.50 & 128.15 & 35.25 & 3.57 & 2 & .19 \\
\hline Clarity of feelings & 132.22 & 128.47 & 113.00 & .27 & 2 & .88 \\
\hline Mood repair & 134.66 & 125.47 & 94.75 & 1.40 & 2 & .50 \\
\hline Male & $(n=79)$ & $(n=47)$ & $(n=8)$ & & & \\
\hline Attention to feelings & 68.35 & 70.65 & 40.56 & 4.22 & 2 & .12 \\
\hline Clarity of feelings & 68.00 & 67.32 & 63.63 & .09 & 2 & .95 \\
\hline Mood repair & 67.31 & 71.32 & 46.94 & 2.71 & 2 & .26 \\
\hline
\end{tabular}

Note: $\mathrm{Df}=$ degrees of freedom 
The same analysis was conducted within different subgroups: according to the school year that the adolescent attended (first, third and fifth-year) and by gender. Regarding the comparison by grade, there were no cases of high consumers in the first school year group, but significant differences in attention to feelings were found between low and middle-frequency consumers ( $U$ = 595.00; $Z=-2.51 ; p=.01$ ) in favor of low-frequency consumers. The Cliff's delta shows a medium-low effect size (-.40). Secondly, there were no significant differences between low, medium and high-frequency consumers in the third school year group. Finally, in the fifth school year group a difference was found within attention to feelings $(\chi 2(2)=11.42 ; p<.01)$ (see Table 3 ). The post hoc analysis showed differences between low and high frequency consumers $(U=110.00, Z=-3.23, p<.01)$ and between the medium and high frequency consumers $(U=20.50, Z$ $=-3.30, p<.01)$, observing that the level of attention to feelings was always higher for those who had less frequent consumption (see Table 4).

Table 4. Pos hoc analysis: IE and frequency alcohol consumption

\begin{tabular}{|c|c|c|c|c|c|c|}
\hline & \multicolumn{3}{|c|}{ Mean Rank } & \multirow[b]{2}{*}{$U$} & \multirow[b]{2}{*}{ Z } & \multirow[b]{2}{*}{$\mathrm{p}$} \\
\hline & Low & Medium & High & & & \\
\hline \multirow[t]{4}{*}{ Attention to feelings } & $(n=228)$ & $(n=156)$ & $(n=10)$ & & & \\
\hline & 193.04 & 191.71 & & 17660.50 & -.12 & .91 \\
\hline & 122.46 & & 52.05 & 465.50 & -3.17 & $.00 * *$ \\
\hline & & 86.24 & 40.80 & 353.00 & -2.90 & $.00 * *$ \\
\hline \multirow[t]{3}{*}{ Attention to feelings (seniors) } & $(n=24)$ & $(n=89)$ & $(n=8)$ & & & \\
\hline & 58.92 & 56.48 & & 1022.00 & -.32 & .75 \\
\hline & 19.65 & & 7.06 & 20.50 & -3.30 & $.00 * *$ \\
\hline
\end{tabular}

Note: ${ }^{*} \mathrm{p}<.05$ corrected by Bonferroni. ${ }^{* *} \mathrm{p}<.01$ corrected by Bonferroni.

The Cliff's delta showed a medium-high effect size between medium and high-frequency consumers (-.69) and a high effect size between low and high frequency consumers (-.79). No differences were found in attention to feelings, clarity of feelings and mood repair regarding the levels of alcohol consumption frequency between males and females (see Table 3 and 4).

Finally, as observed in Table 2, since frequency of alcohol consumption increases with age, and given that differences in the levels of some emotional intelligence aspects were found within the age groups when taken into consideration the alcohol consumption frequency, a linear regression was performed to determine if the level of attention to feelings, clarity of feelings, and mood repair in the different age groups can explain the frequency of alcohol consumption level in this sample. The analysis was performed with the whole sample and then repeated in males and females separately. The regression analysis with the complete sample showed a

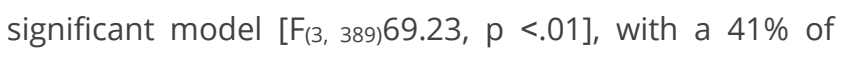
explained variance. The variables that significantly predicted the frequency of alcohol consumption were attention to feelings $(\beta=-.319, \mathrm{t}(389)=-2.67 \mathrm{p}<.01)$, indicating that low attention to feeling increases the frequency of consumption, and age $(\beta=.72$, $\mathrm{t}(389)=16.48$ $p<.01$ ), which indicates that consumption increases as adolescents get older. The regression analysis in women showed that the model was significant $\left[\mathrm{F}_{(4,255) 41.56, \mathrm{p}}\right.$ $<.01$ ], with a $39 \%$ of explained variance. Within the model, when analyzing the effects of each of the predictor variables, only age $(\beta=.67, \mathrm{t}(255)=12.74, p<.01)$ and attention $(\beta=-.36, \mathrm{t}(255)=-2.36, \mathrm{p}=.02)$ had a significant effect on the frequency of alcohol consumption, in both cases replicating the relationship found in the complete sample. Finally, the regression analysis in males also showed that the model was significant $\left[F_{(4,129)} 30.07, p<\right.$ $.01]$, with a $47 \%$ of explained variance. Regarding the specific variables that predict the frequency of alcohol consumption, the only one that was significant was age ( $\beta$ 
$=.85, \mathrm{t}(129)=10.88 \mathrm{p}<.01)$, suggesting, again, that older the participants consume larger amounts of alcohol (see Table 5).

Table 5. Regression analysis on frequency alcohol consumption

\begin{tabular}{|c|c|c|c|c|c|c|c|c|c|c|c|c|}
\hline & \multicolumn{3}{|c|}{ A } & \multicolumn{3}{|c|}{ C } & \multicolumn{3}{|c|}{$\mathrm{R}$} & \multicolumn{3}{|c|}{$\mathrm{E}$} \\
\hline & $\beta$ & $\mathrm{t}$ & $P$ & $\beta$ & $\mathrm{t}$ & $p$ & $\beta$ & $\mathrm{t}$ & $p$ & $\beta$ & $\mathrm{t}$ & $p$ \\
\hline$F^{\circ}$ & -.32 & 2.67 & .00 & .03 & .24 & .81 & -.02 & .18 & .86 & .72 & 16.48 & .00 \\
\hline Female $F^{\circ}$ & -.36 & -2.36 & .02 & -.04 & -.33 & .74 & -.00 & -.03 & .98 & .67 & -.33 & .00 \\
\hline Male $F^{\circ}$ & -.10 & -.51 & .61 & .06 & .12 & .91 & -09 & -.05 & .60 & -.85 & 10.88 & .00 \\
\hline
\end{tabular}

Note: $A=$ Attention to feelings, $C=$ Clarity of feelings, $E=A g e, F^{\circ}=$ Frequency

\section{DISCUSIÓN}

Emotional intelligence includes a number of emotional skills that are considered important for emotional management and for achieving a healthy adaptation to the context. It includes the perception of the attention paid to the emotions, the perception of the clarity with which they are perceived and the perception about the capacity of recovery of negative emotional states. On the other hand, alcohol is the substance most consumed during adolescence representing a problem for this age group. One of the aims of this work was to study how the frequency with which adolescents consume alcohol relates to emotional intelligence. For that purpose, differences in the levels of attention to feelings, clarity of feelings, and mood repair were compared between three frequency of consumption groups: low, medium, and high. This comparison was also performed dividing the sample into different groups depending on the grades the subjects attended (first, third, and fifth-year students) and according to gender. In addition, the predictive power of emotional intelligence components along with age, on the frequency of alcohol consumption was studied.

Regarding emotional intelligence and the frequency of alcohol consumption, results indicate that adolescents who reported higher levels of attention to feelings were less frequent consumers. On the other hand, other studies found a negative relation between the consumption of alcohol and emotional intelligence (Austin, et al., 2005; Brackett, et al., 2004; Riley \& Schutte, 2003; Trinidad \& Johnson, 2002). It seems that adolescents who perceive themselves as more attentive to their emotions are those who consume alcohol less frequently which is consistent with a study of Moral Jiménez et al. (2005). In reference to that, it is possible that alcohol works as an external resource to face the displeasure that emotional information can generate. These results indicate that those who consume alcohol more often have poorer self-perception in terms of their level of attention to feelings. In other words, the information a person can obtain from the emotions to guide their behavior and thinking adaptively will heavily depend on the attention given to them. Brackett et al. (2004) associated a poor perception of emotions and a difficulty in using the information they provided to an increase in alcohol consumption. Perhaps alcohol consumption works as a way to deal with emotions that are not taken care of, and for this reason, the difference is observed in the frequency with which this substance is ingested. These results differ from those of Ruiz-Aranda, Fernández-Berrocal, Cabello, and Extremera (2006) who found that adolescents who consumed more alcohol reported higher levels of attention to feelings. This differences could indicate either cultural differences or difficulties in the conceptualization and assessment of perceived emotional intelligence. The lack of association between recovery factor and alcohol consumption may be due to the characteristics of TMMS-21. The authors suggest that there is a relationship between the factors of the TMMS-21, stating that if the person does not pay attention to their feelings can hardly be clear at the time of perceiving them, and that if it fails to break them down the recovery will be affected (Salovey, et al., 1995). In this case the differences are observed in the first link of this chain, which provides support to the idea that there is a certain temporal relationship between these factors. 
Regarding the comparisons between the three age groups, in younger adolescents, differences were found between the low and middle-frequency consumers, but there were no cases of high-frequency consumers at this age. In the adolescents that attended third high school year no differences were found while, in older adolescents, differences were found between low and medium frequency consumers with high-frequency ones. Both in the group of women as in the group of men, only age proved to be a significant predictor, indicating that frequency of alcohol consumption increases with age. Brackett et al. (2004) found significant negative associations between emotional intelligence and alcohol consumption in men. On the contrary, in this study, it was only in the group of women that the perception of the attention to feelings was a significant predictor of the frequency of alcohol consumption along with age. The women group results indicate that low attention to feelings predict a higher frequency of alcohol consumption. This could follow the results of previous studies that suggest a higher level of attention to feelings in women (Fernández Berrocal \& Ramos Díaz, 1999; Lasa, et al., 2010; Sánchez Núñez, et al., 2008). It seems that only in the case of women the perception of a level of attention to feelings, would affect the frequency of alcohol consumption, therefore only in the female gender alcohol could function as a way of coping with unattended emotions. These results could be explained in light of the differences in socialization processes in women and men (Gartzia, Aritzeta, Balluerka, \& Barberá, 2012). Women are encouraged to pay more attention and to give more importance to emotions, while men are encouraged to minimize their emotional experience (Sánchez Núñez, et al., 2008). Due to the importance about emotions that women are taught, perhaps in women the low attention to feelings has as a consequence a predisposition to alcohol consumption not observed in men.

Considering that alcohol is the most consumed psychoactive substance during adolescence (OAD, 2012), to analyze the relationship between its consumption and emotional intelligence can provide indications that could result in interventions to modify these naturalized habits in our society. The existence of programs for adolescents that include an emotional instruction that teaches them how to attend to emotions and to use the information they provide could be beneficial in relation to alcohol consumption. As proposed by Larson and Brown (2007), adolescents that repeatedly experience emotional situations in a safe environment can learn to identify emotions as well as their consequences and develop strategies to control them. The existence of programs that allow adolescents to experience an emotionally positive and safe environment, where they learn about the importance of emotional information for their behaviors, will affect emotional management strategies in the context of alcohol consumption.

Future studies could investigate the interference of contextual or cultural variables in the relationships analyzed in this manuscript. Also, information about the evolution of this relationship throughout adolescence would be interesting in order to develop interventions aimed at specific age groups.

This work is not exempt of limitations. As the sample corresponds to two schools, both in Buenos Aires's citym it is necessary to expand the population to increase the external validity of this research.

\section{REFERENCES}

Austin, E. J., Saklofske, D. H., \& Egan, V. (2005). Personality, well-being and health correlates of trait emotional intelligence. Personality and Individual differences, 38(3), 547-558. doi:10.1016/j.paid.2004.05.009

Bermúdez, M. P., Álvarez, I. T., \& Sánchez, A. (2003). Análisis de la relación entre inteligencia emocional, estabilidad emocional y bienestar psicológico. Universitas Psychologica, 2(1), 27-32.

Brackett, M. A., Mayer, J. D., \& Warner, R. M. (2004). Emotional intelligence and its relation to everyday behaviour. Personality and Individual differences, 36(6), 1387-1402. doi:10.1016/S0191-8869(03)00236-8

Calero, A. D. (2013). Versión Argentina de la Trait Meta Mood Scale (TMMS) para adolescentes: Una medida de la inteligencia emocional percibida. Cuadernos de Neuropsicología- Panamerican Journal of Neuropshychology, 7(1), 104-119. doi:10.7714/cnps/7.1.206

Calero, A. D., Schmidt, V., \& Bugallo, L. (2016). Consumo de alcohol y su relación con la autopercepción adolescente Health and Addictions, 16(1), 49- 58. doi:10.21134/haaj.v16i1.259

Cliff, N. (1993). Dominance statistics: Ordinal analyses to answer ordinal questions. Psychological Bulletin, 114, 494-509.

Cremonte, M., Cherpital, C., Bosges, G., Peltzer, R., \& Santángelo, P. (2011). Drinking patterns and DSM-IV alcohol use disorders' criteria in Argentinean Emergency Department patients. Journal of Drug Addiction, Education and Eradication, 6, 15-30.

Chambers, R. A., Taylor, J. R., \& Potenza, M. N. (2003). Developmental Neurocircuitry of Motivation in Adolescence: A Critical Period of Addiction Vulnerability. American Journal of Psychiatry, 160(6), 10411052. doi: 10.1176/appi.ajp.160.6.1041 
Extremera Pacheco, N., Salguero, J. M., \& Fernández-Berrocal, P. (2011). Trait Meta-Mood and Subjective Happiness: A 7-week Prospective Study. Journal of Happiness Studies, 12, 509-517. doi:10.1007/s10902-010-9233-7

Fernández-Berrocal, P., \& Extremera Pacheco, N. (2008). A review of trait meta-mood research. International Journal of Psychology Research, 2(1-2), 39-67.

Fernández Berrocal, P., \& Ramos Díaz, N. (1999). Investigaciones empíricas en el ámbito de la Inteligencia emocional. Ansiedad y Estrés, 5(2-3), 247-260.

Furby, L., \& Beyth- Marom, R. (1992). Risk taking in adolescence: A decisión- making perspective. Developmental review, 12, 1-44. doi:10.1016/0273-2297(92)90002-」

García del Castillo-López, A., García del Castillo, J., \& Marzo Campos, J. (2012). La relevancia de la inteligencia emocional en la prevención del consumo de alcohol. Informació Psicològica, 104, 100-111.

Gartzia, L., Aritzeta, A., Balluerka, N., \& Barberá, E. (2012). Inteligencia emocional y género: más allá de las diferencias sexuales. Anales de psicología, 28(2), 567-575.

Gohm, C. L. (2003). Mood regulation and emotional intelligence: individual differences. Journal of personality and social psychology, 84(3), 594. doi: 10.1037/0022-3514.84.3.594

Gohm, C. L., Baumann, M. R., \& Sniezek, J. A. (2001). Personality in extreme situations: Thinking (or not) under acute stress. Journal of Research in Personality, 35(3), 388-399. doi: 10.1006/jrpe.2001.2321

Goleman, D. (2012). Inteligencia emocional: Editorial Kairós.

Jiménez, M. I., \& López-Zafra, E. (2008). El autoconcepto emocional como factor de riesgo emocional en estudiantes universitarios. Diferencias de género y edad. Boletín de Psicología, 93(1), 21-39.

Jiménez, M. I., \& López-Zafra, E. (2011). Actitudes sociales y adaptación social en adolescentes españoles: el papel de la inteligencia emocional percibida. Revista de Psicología Social, 26(1), 105-117.

Kopera, M., Trucco, E. M., Jakubczyk, A., Suszek, H., Michalska, A., Majewska, A., . . Wojnar, M. (2018). Interpersonal and intrapersonal emotional processes in individuals treated for alcohol use disorder and non-addicted healthy individuals. Addictive Behaviors, 79, 8-13. doi:10.1016/j.addbeh.2017.12.006

Larson, R. W., \& Brown, J. R. (2007). Emotional development in adolescence: What can be learned from a high school theater program? Child Development, 78(4), 1083-1099. doi:10.1111/j.14678624.2007.01054.x

Lasa, N. B., Salguero, J. M., Fernández Berrocal, P., \& Aritzeta, A. (2010). Validación de la versión reducida en castellano del Trait Meta-Mood Scale (TMMS) para la población adolescente Paper presented at the Actas del XI Congreso de Metodologías de las Ciencias Sociales y de la Salud, Málaga, 15-18 septiembre de 2009.

Lischetzke, T., \& Eid, M. (2003). Is attention to feelings beneficial or detrimental to affective well-being? Mood regulation as a moderator variable. Emotion, 3(4), 361. doi:10.1037/15283542.3.4.361
Londoño Pérez, C., García Hernández, W., Valencia Lara, S. C., \& Vinaccia Alpi, S. (2005). Expectativas frente al consumo de alcohol en jóvenes universitarios colombianos. Anales de Psicología, 21(2), 259-267.

Lopes, P. N., Salovey, P., \& Straus, R. (2003). Emotional intelligence, personality, and the perceived quality of social relationships. Personality and Individual Differences, 35(3), 641-658. doi:10.1016/S0191-8869(02)00242-8

Míguez, H. A. (2008). Cultural patterns of social alcohol use in Buenos Aires' students (Argentina). Vertex 20(87), 325-328.

Míguez, H. A. (2009). Patrones culturales de la alcoholización social en estudiantes bonaerenses. Vertex, 20, 325 - 328 .

Moral Jiménez, M. V., Rodríguez Díaz, F. J., \& Sirvent Ruiz, C. (2005). Motivadores de consumo de alcohol en adolescentes: Análisis de diferencias inter-género y propuesta de un continuum etiológico. Adicciones, 17(2), 105-120.

OAD. (2012). Quinta Encuesta Nacional a Estudiantes de Enseñanza Media $2011 . \quad$ Retrieved from http://portal.educacion.gov.ar/files/2013/10/adiccion_quinta_encu esta.pdf

PAHO. (2010). El alcohol: un producto de consumo no ordinario. Investigación y políticas públicas ( $\left.2^{\circ} \mathrm{ed}\right)$.

PAHO. (2014). VI Estudio Nacional sobre Consumo de Sustancias Psi-coactivas en Estudiantes de Enseñanza Media 2014. Buenos Aires: SEDRONAR.

Riley, H., \& Schutte, N. S. (2003). Low emotional intelligence as a predictor of substance-use problems. Journal of drug education, 33(4), 391 398. doi:10.2190/6DH9-YTOM-FT99-2X05

Ruiz-Aranda, D., Fernández-Berrocal, P., Cabello, R., \& Extremera, N (2006). Inteligencia emocional percibida y consumo de tabaco y alcohol en adolescentes. Ansiedad y Estrés, 12(2-3), 223-230.

Salguero, J. M., Palomera, R., \& Fernández-Berrocal, P. (2012). Perceived emotional intelligence as predictor of psychological adjustment in adolescents: a 1-year prospective study. European Journal of Psychology of Education, 27(1), 21-34. doi:10.1007/s10212-011-0063$\underline{8}$

Salovey, P., \& Mayer, J. D. (1990). Emotional intelligence. Imagination, Cognition, and Personality, 9, 185-211. doi:10.2190/DUGG-P24E52WK-6CDG

Salovey, P., Mayer, J. D., Goldman, S. L., Turvey, C., \& Palfai, T. P. (1995). Emotional attention, clarity, and repair: Exploring emotional intelligence using the trait meta-mood scale. In J. W. Pennebaker (Ed.), Emotion, disclosure \& health (pp. 125-151). Washington: American Psychological Association.

Salovey, P., Stroud, L. R., Woolery, A., \& Epel, E. S. (2002). Perceived emotional intelligence, stress reactivity, and symptom reports: Further explorations using the Trait Meta-Mood Scale. Psychology and Health, 17, 611-627. doi:10.1080/08870440290025812

Sánchez Núñez, M. T., Fernández Berrocal, P., Montañés Rodríguez, J., \& Latorre Postigo, J. M. (2008). ¿Es la inteligencia emocional una cuestión de género?: socialización de las competencias 
emocionales en hombres y mujeres y sus implicaciones. Electronic journal of research in educational Psychology, 6(15), 455-474.

Trinidad, D. R., \& Johnson, C. A. (2002). The association between emotional intelligence and early adolescent tobacco and alcohol use. Personality and individual differences, 32(1), 95-105. doi:10.1016 / S0191-8869 (01) 00008-3

Van Schoor, G., Bot, S. M., \& Engels, R. C. (2008). Alcohol drinking in young adults: The predictive value of personality when peers come around. European addiction research, 14(3), 125-133. doi:10.1159/000130416

Volkow, N. D., \& Li, T. (2005). Drugs and alcohol: Treating and preventing abuse, addiction and their medical consequences. Pharmacology \& Therapeutics, 108, 3-17. doi:10.1016/j.pharmthera.2005.06.021

WHO. (2008). Informe sobre la salud en el mundo 2008. La atención primaria de la salud. Retrieved from http://www.who.int/whr/2008/es/.

Williams, F. M., Fernández-Berrocal, P., Extremera Pacheco, N., Ramos Díaz, N., \& Joiner Jr, T. E. (2004). Mood regulation skill and the symptoms of endogenous and hopelessness depression in Spanish high school students. Journal of Psychopathology and Behavioral Assessment, 26(4), 233-240. doi:10.1023/B:JOBA.0000045339.67766.86 